University of Nebraska - Lincoln

DigitalCommons@University of Nebraska - Lincoln

2007

\title{
Oxygenated Interface on Biomass Burn Tar Balls Determined by Single Particle Scanning Transmission X-ray Microscopy
}

\author{
Alexei V. Tivanski \\ Lawrence Berkeley National Laboratory \\ Rebecca J. Hopkins \\ Lawrence Berkeley National Laboratory \\ Tolek Tyliszczak \\ Lawrence Berkeley National Laboratory \\ Mary K. Gilles \\ Lawrence Berkeley National Laboratory
}

Follow this and additional works at: https://digitalcommons.unl.edu/usdoepub

Part of the Bioresource and Agricultural Engineering Commons

Tivanski, Alexei V.; Hopkins, Rebecca J.; Tyliszczak, Tolek; and Gilles, Mary K., "Oxygenated Interface on Biomass Burn Tar Balls Determined by Single Particle Scanning Transmission X-ray Microscopy" (2007). US Department of Energy Publications. 46.

https://digitalcommons.unl.edu/usdoepub/46

This Article is brought to you for free and open access by the U.S. Department of Energy at DigitalCommons@University of Nebraska - Lincoln. It has been accepted for inclusion in US Department of Energy Publications by an authorized administrator of DigitalCommons@University of Nebraska - Lincoln. 


\title{
Oxygenated Interface on Biomass Burn Tar Balls Determined by Single Particle Scanning Transmission X-ray Microscopy
}

\author{
Alexei V. Tivanski, ${ }^{\dagger}$ Rebecca J. Hopkins, ${ }^{\dagger}$ Tolek Tyliszczak, ${ }^{\dagger}$ and Mary K. Gilles ${ }^{*} \dagger$ \\ Chemical Science Division and Advanced Light Source, Lawrence Berkeley National Laboratory, Berkeley, \\ California 94720
}

Received: January 8, 2007; In Final Form: April 24, 2007

\begin{abstract}
Carbonaceous particles originating from biomass burning can account for a large fraction of organic aerosols in a local environment. Presently, their composition, physical and chemical properties, as well as their environmental effects are largely unknown. Tar balls, a distinct type of highly spherical carbonaceous biomass burn particles, have been observed in a number of field campaigns. The Yosemite Aerosol Characterization Study that took place in summer 2002 occurred during an active fire season in the western United States; tar balls collected during this field campaign are described in this article. Scanning transmission X-ray microscopy and near-edge X-ray absorption fine structure spectroscopy are used to determine the shape, structure, and size-dependent chemical composition of $\sim 150$ individual spherical particles ranging in size from 0.15 to 1.2 $\mu \mathrm{m}$. The elemental composition of tar balls is $\sim 55 \%$ atomic carbon and $\sim 45 \%$ atomic oxygen. Oxygen is present primarily as carboxylic carbonyls and oxygen-substituted alkyl (O-alkyl-C) functional groups, followed by moderate amounts of ketonic carbonyls. The observed chemical composition, density, and carbon functional groups are distinctly different from soot or black carbon and more closely resemble high molecular weight polymeric humic-like substances, which could account for their reported optical properties. A detailed examination of the carboxylic carbonyl and $\mathrm{O}$-alkyl-C functional groups as a function of particle size reveals a thin oxygenated interface layer. The high oxygen content, as well as the presence of water-soluble carboxylic carbonyl groups, could account for the reported hygroscopic properties of tar balls. The presence of the oxygenated layer is attributed to atmospheric processing of biomass burn particles.
\end{abstract}

\section{Introduction}

Organic atmospheric aerosols from a variety of natural and anthropogenic sources account for a significant fraction of airborne particulate matter. Biomass burning is one of the major sources of fine organic aerosols. ${ }^{1}$ Because of their abundance, they can have substantial effects on the environment and regional and global climates. Climate effects are typically divided into direct and indirect effects. The direct effect describes the scattering and absorption of solar radiation by aerosol particles, therefore leading to a warming of the atmosphere. Black carbon, sometimes loosely used interchangeably with "soot", strongly absorbs light in the visible region of the electromagnetic spectrum, and its presence is typically identified by measurements made at a single wavelength $(\sim 550 \mathrm{~nm}){ }^{2}$ However, recent laboratory and field studies indicate that some organic aerosols efficiently absorb light in the visible and near-UV region of the spectrum, prompting a review of the definition of black carbon based purely on the light absorption measurements. ${ }^{3-6}$ Light-absorbing organic aerosol is tentatively named "brown carbon" and may be associated with natural humic or fulvic acids, often defined as high molecular weight humic-like substances (HULIS).$^{5,7-9}$ HULIS in atmospheric aerosols can originate from primary sources, including the incomplete breakdown of polymeric carbohydrates and lignin or secondary sources such as $\mathrm{OH}$-induced free radical polymerization. ${ }^{4,9-11}$ Several studies report that HULIS not only leads to the efficient

* Corresponding author. E-mail: MKGilles@lbl.gov.

Chemical Science Division.

$\doteqdot$ Advanced Light Source. absorption of solar radiation in the UV and visible range, but also exhibits a much stronger wavelength dependence at shorter wavelengths than black carbon., ${ }^{2,4}$ These differences in the optical properties of black carbon and HULIS imply that measuring the absorption of solar radiation at a single wavelength in the mid-visible range can lead to inaccurate estimates of black carbon in the atmosphere.

The indirect aerosol effect relates to the ability of particles to act as cloud condensation nuclei $(\mathrm{CCN})$ and facilitate the formation of aqueous aerosol. As CCN concentrations increase, the average cloud droplet size decreases, suppressing precipitation formation. Increasing the aqueous aerosol surface area subsequently increases the radiation reflected from the earth's surface leading to atmospheric cooling. Biomass burn haze can be transported to high altitudes and undergo long-range transport, hence impacting the global climate. ${ }^{12,13}$ Since the CCN activity of organic aerosols depends strongly on the type and concentration of different organic compounds, one of the key factors determining the interplay of direct and indirect effects of biomass burn aerosols on the earth's radiation budget is their chemical composition. The overall climate and environmental effects of increasing atmospheric aerosol concentrations remain largely unknown, primarily due to large uncertainties in the chemical composition of organic aerosols as well as a limited understanding of the chemical transformations and atmospheric lifetimes of particles due to atmospheric processing. ${ }^{14}$ Therefore, understanding global climate and regional haze effects of organic aerosols requires quantitative knowledge of their chemical composition as well as their optical and hygroscopic properties. 
To date, characterization of atmospheric aerosol organic components has primarily involved analysis of water-soluble constituents based on a combination of chromatographic separation and molecular speciation by mass spectrometry and photon nuclear resonance analysis. ${ }^{10}$ The chemical composition of only the soluble fraction is determined and may not reflect the overall aerosol composition due to the presence of insoluble fractions. Thus, there is a clear need to develop alternative techniques for the speciation of organic carbon in atmospheric aerosols. Here, we develop a new approach for the direct quantitative analysis of single organic aerosols based on a combination of scanning transmission X-ray microscopy (STXM) and near-edge X-ray absorption fine structure (NEXAFS) spectroscopy. Combining STXM and NEXAFS spectroscopy provides a unique opportunity to identify functional groups within various regions of individual submicrometer particles.

In this study, a distinct type of biomass burn aerosol called tar balls is investigated. Tar balls have been observed during biomass burn events in a number of field campaigns, in both fresh and aged smoke (a few hours to a few days old). ${ }^{15-17}$ Tar balls are highly spherical, amorphous, carbonaceous particles that may correspond to an intermediate stage in the aging of biomass burn organic particles. Here, we present results on the size-dependent structure and chemical composition of fine tar ball particles (diameters less than a few micrometers) collected during the Yosemite Aerosol Characterization Study of summer 2002 at Yosemite National Park. ${ }^{17}$ The back trajectory analysis for these samples is consistent with a forest fire originating in Oregon whose plume had traveled for about 3 days to the collection site. ${ }^{17}$ Tar balls were present during episodes of high particle light-scattering coefficients, and they were shown to absorb light in the UV and near-IR region of the electromagnetic spectrum as determined by a dual wavelength aethalometer $(\lambda$ $=370$ and $880 \mathrm{~nm}) .{ }^{17} \mathrm{In}$ addition, the hydroscopic properties displayed by tar balls make them efficient CCN. ${ }^{17}$ The ability of tar balls to efficiently scatter and absorb radiation as well as act as CCN has important implications in influencing incoming solar radiation and consecutive climate forcing. However, the chemical composition and molecular speciation of tar balls are not reported in the literature. Therefore, the question remains as to the chemical identity of the species that permits tar balls to efficiently scatter and absorb solar radiation as well as act as CCN. We report for the first time the size-dependent chemical composition and structure of tar balls and provide insight into their optical and hygroscopic properties.

\section{Experimental Section}

Materials. The time-resolved aerosol collector (TRAC), ${ }^{17}$ which is a one-stage jet-to-plate impactor, was used to collect atmospheric samples during the Yosemite Aerosol Characterization Study of summer 2002. Particles were deposited directly onto 400-mesh copper mesh TEM grids coated with carbon type-B (Ted Pella, Inc., Redding, CA) 50-nm-thick films. The TRAC was deployed for a month (Aug 10-Sept 5, 2002), and samples were collected with a time resolution of $15 \mathrm{~min}$. Samples studied here were collected during episodes of high particle light-scattering coefficients occurring in mid-August (day of year, DOY, 228-229) during a biomass smoke/haze event. Standard fulvic acid (2S101F Suwannee River) and humic acid (2S101H Suwannee River) were purchased from the International Humic Substances Society (St. Paul, MN). Thin coatings of the standard acids were deposited directly onto $\mathrm{Si}_{3} \mathrm{~N}_{4}$ windows by applying a gentle contact between the crushed fine powder sample and the $\mathrm{Si}_{3} \mathrm{~N}_{4}$ window and subsequently removing any loose sample.
NEXAFS Spectroscopy Using STXM. Single energy images and carbon, nitrogen, and oxygen K-edge NEXAFS spectra were acquired using the STXM instruments on beamlines 5.3.2 and 11.0.2 of the Advanced Light Source (Berkeley, CA) in a $\sim 0.5$ atm He-filled chamber. For these measurements, the X-ray beam was focused with a custom-made Fresnel zone plate onto the sample, and the transmitted light was detected. The diffraction limited spot size at the sample was determined by the width of the outermost zone of the zone plate, $\sim 35 \mathrm{~nm}$ for these experiments. Images at a single energy were obtained by rasterscanning the sample and collecting transmitted monochromatic light as a function of sample position. Spectra at each image pixel or particular regions of interest on the sample image were extracted from the "stack", which is a collection of images recorded at multiple, closely spaced photon energies across the absorption edge. This enabled spatial mapping of local chemical bonding information. Dwell times used to acquire an image at a single photon energy were typically $0.8-2 \mathrm{~ms}$ per pixel. To quantify the absorbance signal, the measured transmitted intensity ( $I$ ) was converted to optical density (OD) using BeerLambert's law: ${ }^{18} \mathrm{OD}=-\ln \left(I / I_{0}\right)=\mu \rho d$, where $I_{0}$ is the incident photon flux intensity, $d$ is the sample thickness, and $\mu$ and $\rho$ are the mass absorption coefficient and density of the sample material, respectively. Incident beam intensity was measured through the sample-free region of the substrate. Particle spectra were then obtained by averaging over the particles deposited on the substrate. Particles with an absorption of $>1.5$ OD were omitted to ensure the spectra were in the linear regime of BeerLambert's law. The X-ray energy calibration (accuracy of \pm 0.05 $\mathrm{eV}$ ) was afforded by addition of $\mathrm{CO}_{2}$ gas ( $\sim 6$ Torr) to the STXM chamber through comparison of the position of $\mathrm{CO}_{2}$ Rydberg transitions at 292.74 and $294.96 \mathrm{eV} .{ }^{19}$ Carbon K-edge spectra were recorded using a bend magnet beamline (5.3.2) both with and without a nitrogen filter (which suppresses secondorder radiation), as well as with an undulator beamline (11.0.2), which has extremely low contributions from second-order radiation at the carbon K-edge. These spectra were consistent with one another, suggesting that there was no significant contribution from second-order radiation in these experiments.

NEXAFS spectral features arose from transitions of a core electron to an excited state and provided information about chemical bonding. Spectra from 1s electrons were typically in the energy region of $\sim 280-320 \mathrm{eV}$ for $\mathrm{C}, \sim 395-425 \mathrm{eV}$ for $\mathrm{N}$, and $\sim 525-550 \mathrm{eV}$ for $\mathrm{O}$ atoms. The pre-edge background typically arose from the photoionization of valence electrons and the weak but finite absorption of other species at that energy. The post-edge absorbance signal depended on the number of corresponding atoms at the particular edge (i.e., the number of carbon atoms at $\mathrm{C}$-edge or oxygen atoms at $\mathrm{O}$-edge). The total amount of atomic $\mathrm{C}, \mathrm{N}$, or $\mathrm{O}$ was defined as the difference between the corresponding post-edge and pre-edge absorbencies. Pre-edge absorbencies at 280, 395, and $525 \mathrm{eV}$ and post-edge absorbencies at 320,425 and $550 \mathrm{eV}$ were used to quantify the total amount of $\mathrm{C}, \mathrm{N}$, and $\mathrm{O}$ atoms.

Typically, for photon energies close to the absorption edges, a number of sharp transitions arose in the NEXAFS spectra. These transitions arose from electronic resonance transitions of different functional groups and involved both $1 \mathrm{~s}-\pi^{*}$ and/or $1 \mathrm{~s}-$ $\sigma^{*}$ transitions. Peaks arising from transitions due to $\sigma^{*}$ transitions were usually broader than the $\pi^{*}$ peaks, and they were often superimposed on the photoionization continuum. The absorbance energy positions can shift depending on variations in the local coordination environment around different atoms (electron-donating or electron-withdrawing groups). NEXAFS 


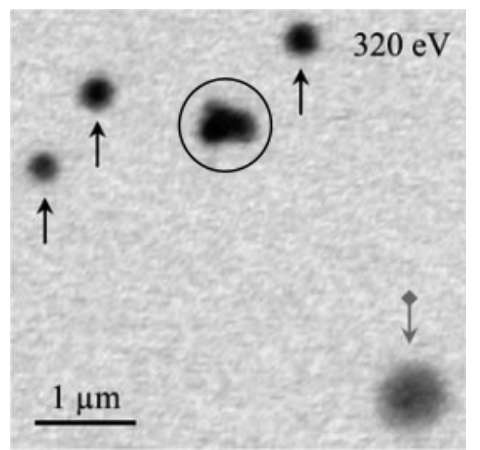

Figure 1. Single energy (320 eV) STXM image of representative particles. Black arrows indicate tar balls, gray arrow shows an organic particle, and an agglomerate particle is indicated by a circle.

peak positions and intensities were used to determine functional groups and ultimately provide quantitative information on the functional groups present. Since the fine structure in the NEXAFS region above the ionization potential was usually broad with overlapping $1 \mathrm{~s}-\sigma^{*}$ transitions, only resonance transitions below the ionization potential were used for subsequent quantification of particle chemical composition. The transition intensity for a functional group was defined as the difference between the absorbance signal at the particular resonance energy and the pre-edge absorbance, normalized to the difference between the corresponding post-edge and preedge absorbencies.

\section{Results and Discussion}

Particle Types Distinguished by STXM. Nearly all aerosol particles collected during the biomass smoke/haze event were carbonaceous with some variation in relative amounts of oxygen and carbon. A combination of STXM and NEXAFS was used to distinguish the main types of carbonaceous particles. Three different major particle types were observed: tar balls, organic particle (with or without) inclusions, and soot. The two most abundant particle types, tar balls and organic particles, were distinguished on the basis of differences in morphology as well as from their NEXAFS spectra. A representative STXM image recorded at $320 \mathrm{eV}$ is shown in Figure 1. Tar balls (indicated by black arrows) are dense, amorphous, spherically shaped particles lacking inorganic inclusions. On repeated X-ray exposures, changes in particle morphology or spectra were not observed. This stability of tar balls to irradiation has been noted previously. ${ }^{15-17}$ Similar to recent field studies, ${ }^{15-17}$ we define this type of carbonaceous particles as "tar balls" owing to their spherical shape, amorphous morphology, and stability to X-ray beam exposure. The highest concentration of tar balls $(\sim 80 \%$ of particles inspected here) was during episodes (DOY 228229) where high particle light-scattering coefficients were measured, which occurred during a biomass smoke/haze event. ${ }^{17}$

The second most abundant particle type, indicated in Figure 1 by a gray arrow, is more optically transparent and diffuse. Although these particles tend to become more spherical when $\leq 0.5 \mu \mathrm{m}$ in diameter, this particle type often exhibits nonspherical morphology. These particles are often larger than tar balls; however, they absorb more weakly and may contain inorganic inclusions of $\mathrm{K}$ and $\mathrm{Ca}$. In the context of this work, we define these as organic particles. This particle type accounted for $\sim 15 \%$ of the inspected particles from DOY 228-229. The corresponding NEXAFS spectra are also used in this article to distinguish between tar balls and organic particles. In addition to tar balls and organic particles, agglomerates were present $(\sim 5 \%)$ in samples from DOY 228-229. A circle surrounds a

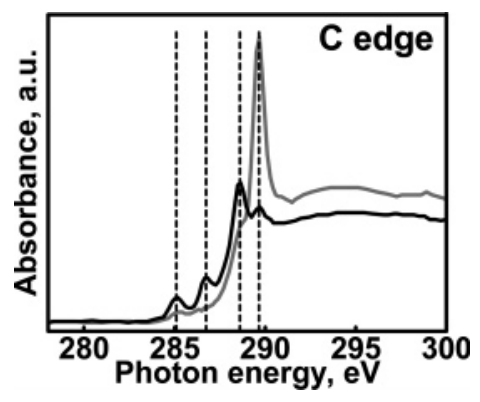

Figure 2. Representative carbon K-edge normalized NEXAFS spectra of a tar ball (black line) and an organic particle (gray line). Vertical dotted lines indicate the absorbance energies, from left to right, at 285.1, 286.7, 288.5, and $289.5 \mathrm{eV}$.

typical agglomerate particle in Figure 1. While some agglomerates were present, only individual spherical particles without inclusions were studied. Finally, a minor amount of soot $(<1 \%)$ was also present as identified from NEXAFS spectra and particle morphology. ${ }^{20,21}$

Speciation of Carbon and Oxygen Functional Groups Using STXM/NEXAFS Spectroscopy. In this work, $\sim 150$ individual spherical particles were studied. The particle diameter was determined from the radial profile from STXM images recorded at the carbon post-edge energy of $320 \mathrm{eV}$. An outline of the method and the resultant particle size distribution are presented in the Supporting Information. The range of particle sizes studied ( $\sim 0.15$ to $1.5 \mu \mathrm{m}$ ) overlaps well with that of Hand et al. ${ }^{17}(\sim 0.1$ to $1.5 \mu \mathrm{m})$ measured using scanning electron microscopy (SEM). On the basis of the overlap of sizes and that our samples and those of Hand et al. were collected either immediately before or after one another using the same TRAC, we assume similar particle types and distribution as Hand et al. Hence, we assume their results obtained on the optical and hygroscopic properties of tar balls for a similar particle distribution hold for our analysis. Additionally, we use their SEM with energy-dispersed X-ray (EDX) result showing that tar balls consist predominantly of $\mathrm{C}, \mathrm{O}$, and $\mathrm{N}$ atoms. We did not use the identical samples studied by Hand et al. to minimize any possible chemical changes in the tar balls that may have occurred during electron beam exposure.

To elucidate the chemical structure of tar balls, as well as distinguish tar balls from organic particles, NEXAFS spectra at the carbon $(\mathrm{C})$, nitrogen $(\mathrm{N})$, and oxygen $(\mathrm{O}) \mathrm{K}$-edges were collected. Typical C K-edge NEXAFS spectra for a tar ball (black line) and an organic particle (gray line) are shown in Figure 2. The constant pre-edge background is subtracted from the spectra and normalized to the same total carbon absorbance. Therefore, spectral differences correspond to differences in chemical structure and not particle thickness. A number of sharp resonances are identified clearly in the NEXAFS spectra. The tar ball C-edge spectrum contains four sharp resonance transitions at 285.1, 286.7, 288.5, and $289.5 \mathrm{eV}$. Two of these transitions are clearly present in the organic particle spectrum (285.1 and $289.5 \mathrm{eV}$ ) in addition to a shoulder at $288.5 \mathrm{eV}$. Although not present in this particular organic particle, occasionally a $286.7 \mathrm{eV}$ peak is observed in organic particles. The distinction between these two particle types is explored in greater detail in the following sections.

The NEXAFS peak assignments are based on reported assignments ${ }^{18,20-31}$ as well as our own observations. Table 1 presents a set of four sharp C-edge transitions observed in the tar ball spectrum (Figure 2) and corresponding functional groups that can contribute to the peak intensity. The absorption band at $285.1 \mathrm{eV}$ is unambiguously assigned to a $1 \mathrm{~s}-\pi^{*}$ transition 
TABLE 1: Set of Four Main C-Edge NEXAFS Transitions and Assignments for the Tar Ball Spectrum Shown in Figure 2

\begin{tabular}{|c|c|c|}
\hline energy, eV & $\operatorname{transition}(\mathrm{s})$ & functionality \\
\hline 285.1 & $1 \mathrm{~s} \rightarrow \pi^{*}$ & protonated/alkylated aromatic $\mathrm{C}$ \\
\hline 286.7 & $1 \mathrm{~s} \rightarrow \pi^{*}$ & $\begin{array}{l}\text { ketone } \mathrm{C}=\mathrm{O} \text {, } \\
\text { carbonyl-substituted aromatic } \mathrm{C} \text {, } \\
\text { phenolic } \mathrm{C}-\mathrm{OH}\end{array}$ \\
\hline 288.5 & $1 \mathrm{~s} \rightarrow \pi^{*}$ & carboxylic carbonyl $\mathrm{COOH}$ \\
\hline 289.5 & $\begin{array}{l}1 \mathrm{~s} \rightarrow 3 \mathrm{p} / \sigma^{*} \\
1 \mathrm{~s} \rightarrow \pi^{*}\end{array}$ & $\begin{array}{l}\text { O-alkyl-C } \\
\text { carbamide }\end{array}$ \\
\hline
\end{tabular}

of protonated and alkyl-substituted aromatic carbon functional groups. ${ }^{18,20-22,25-28,30}$ Ketone $\mathrm{C}=\mathrm{O}$, carbonyl-substituted aromatic $\mathrm{C}$, and phenolic $\mathrm{C}-\mathrm{OH}$ can all have resonances at 286.7 eV.22,25,30,31 Hence, an unambiguous assignment of this peak is not possible. However, as demonstrated below, combining the $\mathrm{C}$ - and O-edge spectra provides additional information about this transition. The strong absorption at $288.5 \mathrm{eV}$ is assigned to the $1 \mathrm{~s}-\pi^{*}$ transition of carboxylic carbonyl. ${ }^{22,23,25,30,31}$ This is in accordance with the fact that, because of the electronwithdrawing nature of $\mathrm{O}$ in the $\mathrm{C}=\mathrm{O}$ bonding, the corresponding carboxylic group transition appears at transition energies $\sim 3$ $\mathrm{eV}$ above the $\mathrm{C}=\mathrm{C}$ transition. ${ }^{18}$ Finally, the resonance transition at $289.5 \mathrm{eV}$ can be attributed to oxygen-substituted alkyl carbons (O-alkyl-C), representing polysaccharides and alcohol groups, or alternatively carbamide groups..$^{22,25,31,32}$ The organic particle spectrum shown in Figure 2 has significantly stronger transition intensity at $289.5 \mathrm{eV}$ than the tar ball spectrum. The O-edge NEXAFS spectra collected over the same particles (Figure S1 in the Supporting Information) show strong $1 \mathrm{~s}-\pi^{*}$ carbonyl peaks at 531.8 and $532.5 \mathrm{eV}$ for the tar ball and the organic particle, respectively. This observation implies that the C-edge peak at $289.5 \mathrm{eV}$ for the organic particle largely corresponds to $1 \mathrm{~s}-\pi^{*}$ carbamide carbonyl transition. For the tar ball O-edge spectrum, a relatively weak shoulder is evident at $\sim 532.5 \mathrm{eV}$ (Figure S1 in the Supporting Information), suggesting that while the peak at $289.5 \mathrm{eV}$ is primarily from O-alkyl-C groups, a small number of carbamide groups may also be present. As discussed below, the total number of $\mathrm{N}$ atoms in tar balls is significantly less than the number of carbon or oxygen atoms, which supports the assignment of the $289.5 \mathrm{eV}$ transition in C-edge tar ball spectrum to O-alkyl-C functional groups.

The detailed assignment of the resonance transition at 286.7 $\mathrm{eV}$ is discussed below; here, we distinguish tar balls from organic particles on the basis of differences in their NEXAFS spectra. For large particles, such as those shown in Figure 1, the distinction between the tar balls and organic particles is apparent from differences in morphology and X-ray absorption signal. However, for particle sizes $\leq 0.5 \mu \mathrm{m}$, the similarity in shape makes morphological distinction challenging, if not impossible. In contrast, as shown in Figure 2, NEXAFS spectra for these particle types differ significantly from one another. The most striking differences are the peak intensities at 288.5 $\mathrm{eV}$ (carboxylic carbonyl) and $289.5 \mathrm{eV}$ (O-alkyl-C and carbamide). While the tar ball spectrum in Figure 2 is representative for all tar balls studied, the organic particle spectra exhibit greater variability. For example, the ratio of the transition intensity at 288.5 and $289.5 \mathrm{eV}$ can vary by factors of 2 to 3 for organic particles. While no peak or shoulder at $286.7 \mathrm{eV}$ is observed in the organic particle NEXAFS spectrum shown in Figure 2, this peak is present for some organic particles. Hence, a particle type distinction based on the relative intensities of the $1 \mathrm{~s}-\pi^{*}$ transitions at $286.7 \mathrm{eV}$ is difficult since the intensities for both particle types may be similar in some cases. On the other hand, in the NEXAFS spectra of organic particles there

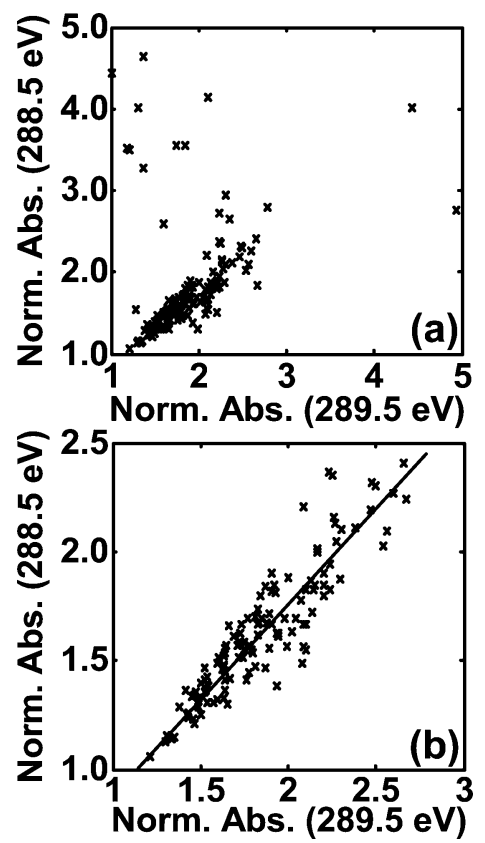

Figure 3. Correlation functions between the intensities at energies 288.5 and $289.5 \mathrm{eV}$ (a) for all $\sim 150$ inspected particles and (b) for $\sim 130$ tar balls. The crosses are the data, and the solid line is the fit to the straight line with zero intercept.

is greater variability in the carboxylic carbonyl peak relative to the peak at $289.5 \mathrm{eV}$, as compared to the tar ball spectra where the relative intensity of these two peaks is nearly constant. Therefore, the uncertainty in the morphological differences for the submicrometer particles can be overcome by taking advantage of these spectral differences, and particle types can be distinguished on the basis of differences in chemical structure. As a result, tar balls are defined by both particle morphology and chemical composition.

Figure 3 a displays the correlation between the intensities at energies of 288.5 and $289.5 \mathrm{eV}$. As the intensities are normalized to the total carbon absorbance, typically $\sim 0.2$ to $0.3 \mathrm{OD}$, the normalized absorbencies are larger than the absolute absorbance $(<1.5 \mathrm{OD})$ measured for the particles. As all spherically shaped particles are plotted in Figure 3, the correlation function indicates the relative amounts of functional groups present in both particle types, tar balls and organics. In Figure 3a, the majority of particles displays a clear positive correlation between the two functional groups, and the correlation fits a straight line with a zero intercept. From this correlation, and the fact that the majority of the particles examined were tar balls, we conclude that for tar balls the ratio of peak intensities at energies of 288.5 and $289.5 \mathrm{eV}$ is constant and independent of particle size. We employ this observation to define tar balls on the basis of the fixed relative intensity of these groups. By removing $\sim 20$ particles with intensity ratios that significantly deviate from this fit, the fit of the remaining $\sim 130$ tar balls has a slope of $0.9 \pm$ 0.18 and a zero intercept and is shown in Figure $3 \mathrm{~b}$.

A number of different carbon functional groups have transitions that can overlap in energy. To aid in peak assignments, $\mathrm{O}$ and N K-edge spectra were collected from the same particles. This data are particularly useful to determine the functional group responsible for the peak at $286.7 \mathrm{eV}$. Figure $4 \mathrm{a}-\mathrm{c}$ shows representative $\mathrm{C}, \mathrm{N}$, and $\mathrm{O} \mathrm{K}$-edge NEXAFS spectra acquired from the same tar ball particle with the constant pre-edge background signal subtracted. The pre-edge background was determined by linear extrapolation of the pre-edge absorbance signal. From the difference between the absorption at the highest 

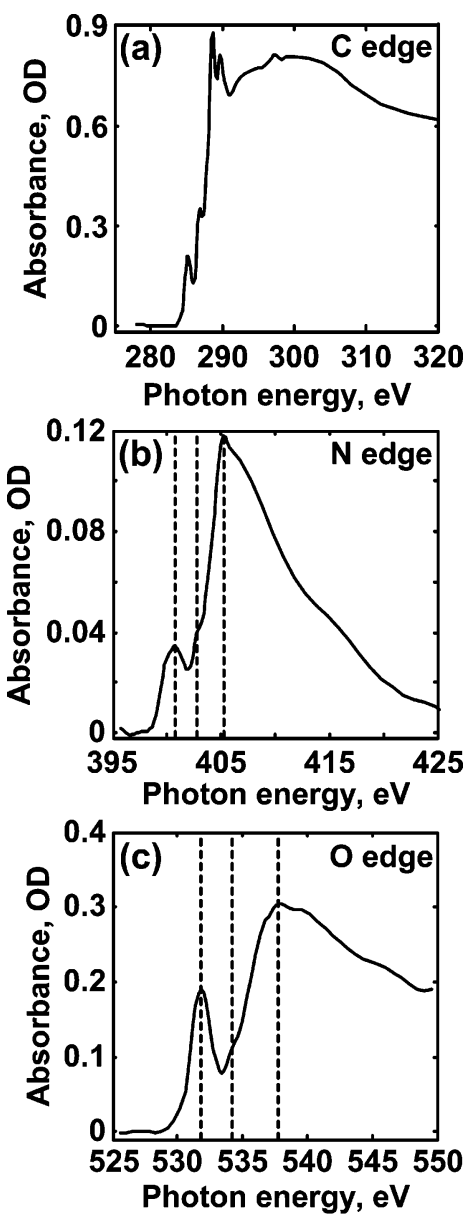

Figure 4. Representative $\mathrm{C}(\mathrm{a}), \mathrm{N}(\mathrm{b})$, and $\mathrm{O}$ (c) K-edge NEXAFS spectra of a tar ball. Vertical dotted lines indicate the absorbance energies at 400.7, 402.7, and $405.2 \mathrm{eV}$ for N-edge, and 531.8, 534.5, and $538 \mathrm{eV}$ for O-edge.

energy minus the absorption at the lowest energy for each edge, it is apparent that the absorption for $\mathrm{N}$ is considerably less than that for $\mathrm{C}$ or $\mathrm{O}$ (a factor of $\sim 20$ less). The spectra presented in Figure 4 indicate a significant absorbance for $\mathrm{C}$ and $\mathrm{O}$. Since the mass absorption coefficients for atomic $\mathrm{C}, \mathrm{N}$, and $\mathrm{O}$ are similar (the difference is less than a factor of 2), ${ }^{33}$ this implies that $\mathrm{N}$ is a minor constituent of tar balls compared to $\mathrm{C}$ and $\mathrm{O}$. This observation is useful in determining the elemental composition of tar balls where we will neglect the $\mathrm{N}$ contribution to their composition, as discussed below.

As seen in Figure $4 b$ in the N K-edge NEXAFS spectrum, a well-defined peak at $400.7 \mathrm{eV}$, a weak shoulder at $\sim 402.7 \mathrm{eV}$, and a broad peak at $\sim 405.2 \mathrm{eV}$ are observed. The transitions at 400.7 and $405.2 \mathrm{eV}$ can be attributed to amine functional groups. ${ }^{26,34,35} \mathrm{~A}$ shoulder at $\sim 402.7 \mathrm{eV}$ likely corresponds to the carbamide groups, ${ }^{32}$ whose minor presence is confirmed from the C-edge NEXAFS data. We note that the peak assignments presented here for the N-edge tar ball spectra are based purely on the peak absorbance energies and should not be considered as absolute. Experimental studies of model compounds, beyond the scope of the present work, would be necessary to assign these peaks unambiguously.

Several transitions in the O-edge spectrum are indicated in Figure 4c, including a sharp peak at $531.8 \mathrm{eV}$, a shoulder at $\sim 534.5 \mathrm{eV}$, and a broad $1 \mathrm{~s}-\sigma^{*}$ peak at $\sim 538 \mathrm{eV}$. The $\sim 534.5$ $\mathrm{eV}$ shoulder can be assigned to a phenolic $\mathrm{C}$ functional group. ${ }^{18,31}$ The peak at $531.8 \mathrm{eV}$ indicates carbonyl functional

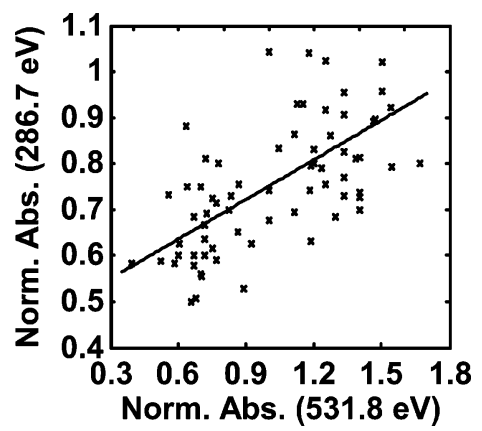

Figure 5. Correlation function between the normalized intensities of resonance transitions at 286.7 and $531.8 \mathrm{eV}$ for $\sim 70$ tar balls. Data is shown as crosses, and fit is shown as a solid line.

groups. ${ }^{31,32}$ To determine if a correlation exists between the oxygen resonance transition at $531.8 \mathrm{eV}$ and an absorption band at the C-edge, a set of corresponding $\mathrm{C}$ - and O-edge spectra was collected for $\sim 70$ tar balls. Correlation functions were plotted between the normalized absorbance intensity at 531.8 $\mathrm{eV}$ (O-edge) and that of each $1 \mathrm{~s}-\pi^{*}$ transition in the C-edge spectra. Figure 5 shows the correlation with the $286.7 \mathrm{eV}$ peak (C-edge) and the fit (solid line). This correlation implies that both transitions originate from the same $\mathrm{C}$ and $\mathrm{O}$ functional groups. On the basis of the peak energy positions and this correlation, we determined that these two peaks arise from ketonic carbonyl functional groups. No correlations between the O-edge peak at $531.8 \mathrm{eV}$ with the remaining three peaks in the C-edge spectra were observed.

The relatively weak correlation $\left(R^{2} \approx 0.4\right)$ between the intensities of the transitions at 531.8 and $286.7 \mathrm{eV}$ could be due to several reasons. First, a shoulder at $534.5 \mathrm{eV}$ (phenolic C) in the O-edge spectrum is consistent with some contribution at $286.7 \mathrm{eV}$ in the C-edge spectrum. Second, carbonylsubstituted aromatic $\mathrm{C}$ can also contribute to the observed peak at $286.7 \mathrm{eV}$. Therefore, there may be contributions to the single peak at $286.7 \mathrm{eV}$ from several broader peaks overlapping from phenolic $\mathrm{C}$ or carbonyl-substituted aromatic carbon. Finally, the $531.8 \mathrm{eV}$ O-edge peak could be broadened and/or its intensity altered because of carbonyl functional groups other than the ketone moiety. The relatively weak correlation between the peak intensities at 286.7 and $531.8 \mathrm{eV}$ is likely to result from a combination of these factors.

In summary, NEXAFS spectroscopy of the C- and O-edge revealed that tar balls primarily consist of protonated/alkylated aromatic $\mathrm{C}$, ketonic carbonyl, carboxylic carbonyl, and $\mathrm{O}-$ alkyl-C functional groups, with a minor presence of phenolic carbon functional groups. The minor amount of $\mathrm{N}$ functional groups could arise from amine and carbamide groups.

Shape, Density, and Elemental Composition of Tar Balls. The shape, density, and elemental composition of tar balls are examined quantitatively to understand the chemical and physical properties that give rise to their ability to efficiently scatter and absorb solar radiation. First, we describe experimental measurements and theoretical models that allow determination of a 3D particle shape using a combination of 2D STXM and NEXAFS spectroscopy. The averaged absorbance signal $\langle\mathrm{OD}(d)\rangle$ through a perfectly spherical particle of uniform density $\rho$ and diameter $d$ can be determined from the following equation

$$
\begin{aligned}
&\langle\mathrm{OD}(d)\rangle=\frac{2}{d} \int_{0}^{d / 2} 2 \mu \rho \sqrt{(d / 2)^{2}-x^{2}} \mathrm{~d} x= \\
& \frac{\rho \mu d}{2 \sin (1)}=A \rho \mu d
\end{aligned}
$$



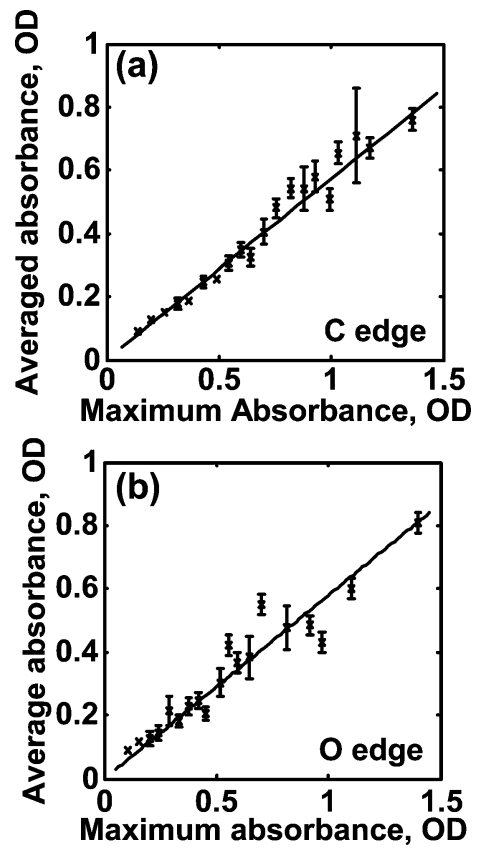

Figure 6. Averaged absorbance versus maximum absorbance plots, showing linear fits for (a) $320 \mathrm{eV}$ and (b) $550 \mathrm{eV}$ photon energies.

where $A$ is the constant $A=1 / 2 \sin (1) \approx 0.59$ for a perfect sphere. Since the maximum absorbance corresponds to the signal through the center of a sphere, maximum optical density is $\mathrm{OD}_{\max }(d)=\rho \mu d$. Therefore, a plot of averaged absorbance versus maximum absorbance for a spherical particle should be linear with slope $A=0.59$ and zero intercept.

Figure 6 plots the experimentally obtained averaged absorbance versus the maximum absorbance (crosses with error bars) for both (a) C-edge at $320 \mathrm{eV}$ and (b) O-edge at $550 \mathrm{eV}$. Each cross represents the mean absorbance value for approximately seven particles assigned to $\sim 50$-nm-wide bins on the basis of their calculated diameters. The uncertainty is the standard deviation of the mean. This averaging decreases uncertainty because of small variability in NEXAFS spectra from particle to particle. Standard deviations smaller than the cross size are not shown. The observed dependencies are linear, consistent with an analytical model that assumes a perfectly spherical particle of uniform density. Straight lines fit both plots with zero intercepts, illustrated in Figure 6 . The fit to the data yields slopes of $0.59 \pm 0.03$ and $0.6 \pm 0.05$ for the $\mathrm{C}$ - and O-edges, respectively. These slopes are in excellent agreement with the predicted slope of 0.59 . This implies that the tar balls are indeed perfect spheres of uniform densities, without a corelike structure, and that the majority of $\mathrm{C}$ and $\mathrm{O}$ atoms is homogeneously distributed throughout the tar ball. This analysis is not sensitive to a thin coating (on the order of the STXM spatial resolution $\sim 35 \mathrm{~nm}$ ) on the particle interface. Such an interface would be averaged out. Therefore, while the vast majority of $\mathrm{O}$ and $\mathrm{C}$ atoms is distributed uniformly throughout the particle, the presence of a thin layer cannot be determined from this analysis alone. In a subsequent section, additional analysis demonstrates that a thin coating is present with a chemical composition distinctly different from that of the entire particle volume.

To quantify the elemental composition of tar balls, we first describe an analytical model that illustrates the relationship between absorbance signals for a mixture of two elements. As mentioned above, the similarity in the particle size distribution studied here and by Hand et al. ${ }^{17}$ from samples collected 15 min apart allows us to use their SEM/EDX results directly. In particular, they determined that tar balls consist predominantly of $\mathrm{C}, \mathrm{O}$, and $\mathrm{N}$, with $\mathrm{C}+\mathrm{O}+\mathrm{N}>95 \%$ for the majority of tar balls. However, they were not able to quantify the relative contributions of atomic C, O, and N. NEXAFS spectroscopy at $\mathrm{C}-, \mathrm{N}-$, and $\mathrm{O}$-edges allows direct quantitative determination of these constituents. As noted above, the total $\mathrm{O}$ or $\mathrm{C}$ was typically $\geq 20$ times larger than the total $\mathrm{N}$ present for tar balls. Therefore, we approximate tar balls as a two-component mixture consisting of carbon and oxygen.

Generally, for a material containing $x_{i}$ atoms of type $i$ with atomic weight $Z_{i}$, the mass absorption coefficient $\mu(E)$ is obtained from the atomic weight scaled sum of the mass absorption cross sections of the constituent atoms by ${ }^{18}$

$$
\mu(E)=\frac{\sum_{i} Z_{i} \mathrm{x}_{i} \mu_{i}(E)}{\sum_{i} x_{i} Z_{i}}
$$

This approximation neglects interactions between the atoms in the material and is generally valid for photon energies sufficiently far from absorption edges. ${ }^{18}$ Assuming the tar balls contain only carbon and oxygen, eq 2 can be rewritten as the following:

$$
\mu(E)=\frac{Z_{\mathrm{O}} x_{\mathrm{O}} \mu_{\mathrm{O}}(E)+Z_{\mathrm{C}} x_{\mathrm{C}} \mu_{\mathrm{C}}(E)}{Z_{\mathrm{O}} x_{\mathrm{O}}+Z_{\mathrm{C}} x_{\mathrm{C}}}
$$

where $\mu_{\mathrm{O}}, Z_{\mathrm{O}}$, and $\mu_{\mathrm{C}}, Z_{\mathrm{C}}$ are the mass absorption coefficients and atomic weights for oxygen and carbon atoms, respectively. As demonstrated above, a tar ball is a perfect sphere of uniform density with the majority of carbon and oxygen atoms homogeneously distributed throughout the particle volume. Therefore, combining eqs 1 and 3, one obtains:

$$
\langle\mathrm{OD}\rangle(E, d)=A \rho \frac{Z_{\mathrm{O}} x_{\mathrm{O}} \mu_{\mathrm{O}}(E)+Z_{\mathrm{C}} x_{\mathrm{C}} \mu_{\mathrm{C}}(E)}{Z_{\mathrm{O}} x_{\mathrm{O}}+Z_{\mathrm{C}} x_{\mathrm{C}}} d
$$

Equation 4 suggests that the averaged absorbance, at energies sufficiently far from absorption edges, should have a linear dependence with particle diameter. The pre-edge and post-edge photon energies at 280 and $320 \mathrm{eV}$ for C-edge and 525 and $550 \mathrm{eV}$ for O-edge are expected to be sufficiently far from the absorption edges, and no overlapping with electronic transitions of carbon and oxygen functional groups is expected. To eliminate the pre-edge absorbance signal arising from the weak but finite absorption of other species at that energy, the total carbon and total oxygen absorbencies should be considered. Therefore, on the basis of eq 4, plots of total carbon and total oxygen absorbance as a function of particle diameter should be linear with slopes dependent upon the elemental composition and differences in the mass absorption coefficients; 320-280 $\mathrm{eV}$ (for atomic carbon) and 550-525 eV (for atomic oxygen). The mass absorption coefficients are calculated from the atomic scattering factors. ${ }^{33}$ For atomic carbon, one obtains the difference in mass absorption coefficients to be $\mu_{320-280}=3.8 \times 10^{4} \mathrm{~cm}^{2} / \mathrm{g}$ and $\mu_{550-525}=-0.1 \times 10^{4} \mathrm{~cm}^{2} / \mathrm{g}$. Similarly, for atomic oxygen $\mu_{320-280}=-0.2 \times 10^{4} \mathrm{~cm}^{2} / \mathrm{g}$ and $\mu_{550-525}=2 \times 10^{4} \mathrm{~cm}^{2} / \mathrm{g}$.

Figure 7 shows the averaged total carbon (a) and total oxygen (b) absorbance as a function of particle diameter. The observed dependencies are linear, consistent with the analytically predicted dependencies in eq 4 . The averaged pre-edge absorbencies for both $\mathrm{C}$ - and $\mathrm{O}$-edges increase in a manner similar to that of corresponding post-edge signals (results are not shown), confirming that the tar balls can be estimated as a two-component 

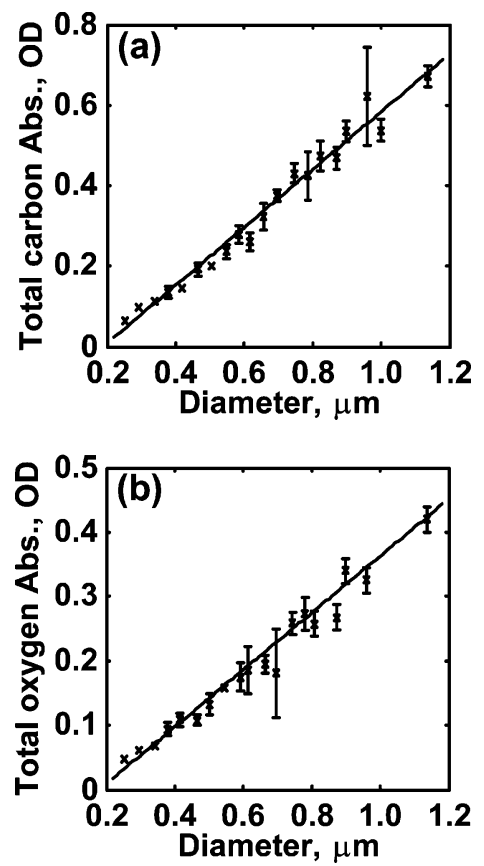

Figure 7. Averaged total carbon (a) and total oxygen (b) absorbance as a function of the particle diameter. Crosses are the data, and solid lines are the fit.

system, with pre-edge signals primarily originated from the presence of $\mathrm{O}$ at the $\mathrm{C}$-edge and $\mathrm{C}$ at the $\mathrm{O}$-edge, respectively. Plots in Figure 7 are fit by straight lines with slopes and intercepts equal to $0.72 \pm 0.05 \mathrm{OD} / \mu \mathrm{m}$ and $-0.14 \pm 0.01 \mathrm{OD}$, respectively, for the carbon edge and $0.45 \pm 0.05 \mathrm{OD} / \mu \mathrm{m}$ and $-0.08 \pm 0.008 \mathrm{OD}$, respectively, for the oxygen edge. The negative values for the intercepts at both edges are due to the presence of minor yet accountable amounts of atoms other than carbon and oxygen (i.e., $\mathrm{N}, \mathrm{H}$, and $\mathrm{S}$ as noted by Hand et al). ${ }^{17}$ The following analysis uses only the fitted slopes to determine tar ball elemental composition.

Combining eq 4 and the slopes from the linear fits from Figure 7, we determined the tar ball density and the atomic ratio of $\mathrm{C}$ to $\mathrm{O}\left(\chi_{\mathrm{c} / \mathrm{o}}\right)$ to be $\chi_{\mathrm{c} / \mathrm{o}}=1.2 \pm 0.1(\sim 55 \% \mathrm{C}, \sim 45 \% \mathrm{O})$ and $\rho=0.75 \pm 0.05 \mathrm{~g} / \mathrm{cm}^{3}$. This density value could be an underestimation as only carbon and oxygen constituents are considered. In addition, any volatile and semivolatile species originally present in the aerosol would evaporate upon collection. The presence of these constituencies would act to increase particle density. A typical value reported in literature for the density of biomass burning carbonaceous aerosols is $\sim 1$ $\mathrm{g} / \mathrm{cm}^{3},{ }^{36,37}$ which is in reasonably good agreement with the value determined here.

The estimated tar ball density is significantly less than soot $\left(\sim 1.8 \mathrm{~g} / \mathrm{cm}^{3}\right),{ }^{38}$ which primarily consists of elemental carbon $(>90 \%)$. Soot particles are often described as black carbon, which is primarily responsible for absorption of solar radiation in the earth's atmosphere. While tar balls can efficiently scatter and absorb solar radiation in the UV and near-IR range of the solar spectra, the differences in particle density and elemental composition indicate that tar balls are not soot. Furthermore, the elemental composition of tar balls is in very good agreement with the literature values for HULIS that indicate mean values of $\sim 55 \%$ and $\sim 36 \%$ for atomic carbon and oxygen, respectively, followed by moderate amounts of atomic hydrogen $(4.8 \%)$, nitrogen $(3.6 \%)$, and sulfur $(0.8 \%) .{ }^{39}$ The literature-reported densities of HULIS samples are often in the range of 1 to 1.5 $\mathrm{g} / \mathrm{cm}^{3},{ }^{40}$ which is closer to the $0.75 \mathrm{~g} / \mathrm{cm}^{3}$ value obtained in

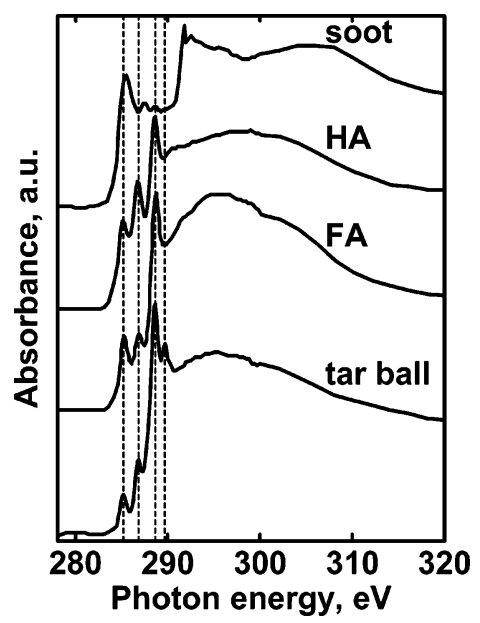

Figure 8. Normalized C K-edge NEXAFS spectra of a soot particle, standard fulvic acid, standard humic acids, and a tar ball particle. The vertical dotted lines show energies of four main transitions of tar ball spectrum.

this work as compared with that of soot $\left(\sim 1.8 \mathrm{~g} / \mathrm{cm}^{3}\right)$. The observed similarities in the elemental composition between tar balls and HULIS provide strong evidence that tar balls belong to a class of humic-like substances formed during biomass burn/ haze events or their subsequent aging. One possible mechanism is based on a gas-to-particle formation mechanism that involves rapid polymerization of $\mathrm{OH}$ radicals present in the atmosphere with phenolic acids generated during the burning of biomass, producing high molecular weight HULIS. ${ }^{11,17}$ However, there is the possibility that some HULIS in tar balls is simply humic matter from lofted soil.

To elucidate the hypothesis that tar balls are more similar to humic-like substances and not black carbon or soot, the NEXAFS spectra of two standard humic and fulvic acids were measured. The representative NEXAFS spectra of both standard acids normalized to the same total carbon absorbance are shown in Figure 8. In addition, a normalized representative spectrum of a soot particle ${ }^{20,21}$ (a minor $(<1 \%$ ) yet accountable presence in the samples collected during the peak of the biomass burn/ haze events) was recorded and is plotted in Figure 8 together with a representative spectrum of a tar ball particle. As clearly seen in Figure 8, the NEXAFS spectra of tar balls and soot differ significantly from each other. Particularly, the aromatic carbon peak (at $285.1 \mathrm{eV}$ ) for the tar balls is narrower and $\sim 4$ times less intense than that for soot, while the strong carboxylic carbonyl peak present in tar balls is absent in soot. Additionally, the soot spectrum exhibits a strong peak at $\sim 292 \mathrm{eV}$, which corresponds to a $1 \mathrm{~s}-\sigma^{*}$ carbon transition with enhancement from a sharp exciton transition at $291.7 \mathrm{eV} .{ }^{41-45}$ These spectral differences support the hypothesis that tar balls are not soot or black carbon. The NEXAFS spectra for both standard humic and fulvic acids are more similar to that of the tar ball spectra with three main transitions in the tar ball spectra (the aromatic $\mathrm{C}$, ketonic carbonyl, and carboxylic carbonyl) present for the standard acid samples. These spectral similarities offer additional support that tar balls are similar to high molecular weight humiclike substances and not soot. The relative proportions of the acid standard functional groups differ from those of tar balls. However, considering that humic and fulvic acids as well as tar balls are not a single chemical species but rather a complex mixture of natural material, the absence of an exact match is not unexpected.

A number of studies propose that HULIS may be derived primarily from biomass combustion, although conclusive evi- 

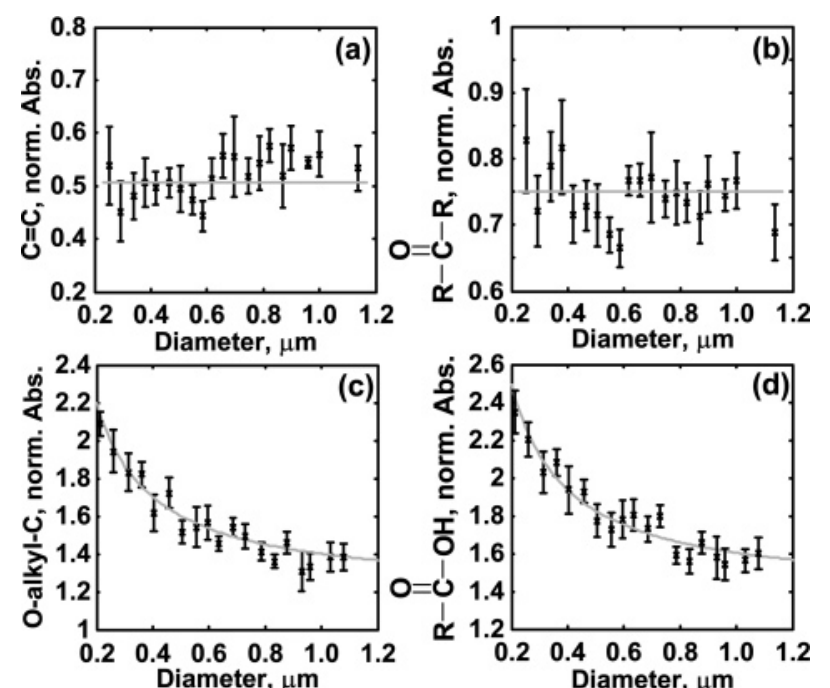

Figure 9. Four main carbon functional groups normalized to the total $\mathrm{C}$ as a function of tar balls diameter for aromatic $\mathrm{C}$ (a), ketonic carbonyl (b), O-alkyl-C (c), and carboxylic carbonyl (d). The crosses are the mean values of the measured normalized intensities, and uncertainties are the standard deviations of mean. Gray solid lines represent curve fits to the data.

dence for this hypothesis has been lacking. ${ }^{10,46}$ The current study confirms the HULIS nature of tar balls originating from a biomass burn. As biomass burning is one of the major sources of fine organic aerosols in the earth's atmosphere, this result shows that biomass burning may represent a significant source of humic-like matter in the atmosphere.

As mentioned previously, tar balls are efficient at scattering and absorbing light in the UV and near-IR region of the solar spectrum. Interestingly, the wavelength dependence for tar ball absorption resulted in absorptions larger than that predicted by the usually assumed $\lambda^{-1}$ dependence. ${ }^{17}$ Similar increases in the imaginary part of the refractive index with decreasing wavelength are found for flame soot. ${ }^{47}$ However, our findings unambiguously show that tar balls are not soot. We argue that the high molecular weight polymeric humic-like structure of the tar balls may be responsible for their optical properties. Indeed, a number of studies report that HULIS efficiently absorbs solar radiation in the UV and near-IR region with increasing absorption at shorter wavelengths. ${ }^{2,4}$ Because biomass burning aerosols, and tar balls in particular, have progressively stronger absorption in the UV and are nongraphitic types of carbon, the techniques commonly used to measure absorption of solar radiation at a single wavelength in the mid-visible range can lead to inaccurate estimates of the black carbon present in the atmosphere. Because of the high abundance of biomass burning organic aerosols in the earth's atmosphere and the similarities of tar balls to HULIS, these uncertainties could significantly alter current estimates of the direct forcing effects of anthropogenic aerosols on global climate.

Tar Ball Size-Dependent Chemical Composition. In the following section, we quantitatively examine the size-dependent chemical composition of tar balls. On the basis of their calculated diameters, we grouped tar balls into bins $\sim 50-\mathrm{nm}$ wide. For every bin, a mean value of the normalized (to the total carbon absorbance) peak intensity was calculated. In Figure 9, aromatic C, ketonic carbonyl, carboxylic C, and O-alkyl-C functional groups, all normalized to the total carbon absorbance, are plotted as a function of particle diameter. Crosses represent the mean values of the measured intensities, and the error bar is the standard deviation of the mean. These normalized intensities are indicative of the relative amounts of the corresponding functional group present in the tar balls.

As clearly seen in Figure 9a,b, the normalized intensities of aromatic $\mathrm{C}$ and ketonic carbonyl functional groups are essentially independent of particle diameter. Averaged values of $\sim 0.5$ and $\sim 0.75$ were obtained from the intercepts for aromatic $\mathrm{C}$ and ketonic carbonyl normalized functional groups, respectively. These are indicated in Figure 9a,b by gray horizontal lines. The absence of a size dependence indicates that the amount of these functional groups present in tar balls scale with particle size similarly to total carbon. As demonstrated previously (Figure 7), the total $\mathrm{C}$ scales linearly with particle size and is uniformly distributed within the particle. Therefore, we conclude that aromatic $\mathrm{C}$ and ketonic carbonyl functional groups are homogeneously distributed throughout the particle volume similar to the total $\mathrm{C}$. This conclusion provides additional evidence that tar balls are highly oxygenated and that the oxygen atoms (from the ketonic carbonyl groups in this case) are homogeneously distributed throughout the particle volume.

The observed trend is drastically different for the carboxylic $\mathrm{C}$ and O-alkyl-C functional groups where a clear size dependence is seen (Figure 9c,d). The normalized intensities of these functional groups clearly decrease with increasing particle diameter. Since the total $\mathrm{C}$ is homogeneously distributed throughout the particle volume, the observed decrease implies a layer at the particle interface containing primarily carboxylic $\mathrm{C}$ and $\mathrm{O}$-alkyl-C functional groups. This can be qualitatively visualized by assuming the number of carboxylic $\mathrm{C}$ and O-alkyl-C functional groups within the layer is directly proportional to the particle area, while the total $\mathrm{C}$ is directly proportional to the particle volume. In this case, the ratio of the number of functional groups to the total $\mathrm{C}$ is directly proportional to the ratio of particle area to particle volume. For a spherically shaped particle, this ratio is inversely proportional to the particle diameter; therefore, if an oxygenated layer exists on the particle interface, a decrease in the ratio of the number of carboxylic $\mathrm{C}$ and $\mathrm{O}$-alkyl-C functional groups to the total $\mathrm{C}$ is expected.

Before quantifying the oxygenated layer, we first semiquantitatively estimate the tar ball chemical composition. Since the number of carboxylic $\mathrm{C}$ and $\mathrm{O}$-alkyl-C functional groups change with particle size, we use the most probable tar ball size of $\sim 500$ $\mathrm{nm}$ (Figure S3 in the Supporting Information). If one assumes similar absorption cross sections ${ }^{18}$ for four main functional group transitions, the results from Figure 9 would lead to a typical tar ball being composed of $\sim 39 \%$ carboxylic carbonyl and $\sim 35 \%$ O-alkyl-C, followed by moderate amounts of ketonic carbonyl $(\sim 16 \%)$ and aromatic $C(\sim 10 \%)$ functional groups. However, as the cross section is generally affected by the character of the excited state, this estimate of the tar ball functional group composition should be considered qualitative.

Quantifying the oxygenated layer requires several assumptions. First, the plots of averaged absorbencies versus maximum absorbencies for both $\mathrm{C}$ - and O-edges (Figure 6) are linear and do not reveal the presence of an oxygenated layer. In the presence of a thin interfacial layer, the plots in Figure 6 would remain linear as estimates of the total absorbencies of $\mathrm{C}$ and $\mathrm{O}$ are obtained at energies away from the resonance transitions and would not be sensitive enough to reveal this size dependence. Therefore, we assume that the oxygenated layer is thin relative to the particle diameter. This assumption is supported by the semiquantitative measurements of electron energy loss maps of a tar ball of Hand et al., ${ }^{17}$ where the $\mathrm{O}$ concentration was strongly enhanced in a $\sim 30$-nm-thick outer region of the 
particle. Our assumption of a thin oxygenated layer is validated by inspecting the ratio of single energy STXM images for the same tar ball recorded at the photon energy of the resonance transition for the carboxylic $\mathrm{C}$ or O-alkyl-C functional groups to an image at the energy at the approximate base of the peak (287.3 and $289.2 \mathrm{eV}$ for the carboxylic C or O-alkyl-C, respectively). The ratio of single energy STXM images does not reveal a signal enhancement at the particle interface for these functional groups, confirming the assumption that the oxygenated layer is thin and on the order of STXM spatial resolution.

Second, we assume that the carboxylic C and O-alkyl-C functional groups are homogeneously distributed within the oxygenated layer of uniform thickness. This assumption is supported by the tar ball shape analysis, which indicates the particles are perfect spheres with $\mathrm{C}$ and $\mathrm{O}$ atoms homogeneously distributed throughout the particle volume. Third, we assume a uniform thickness for the oxygenated layer for all particle sizes. While this assumption may be simplistic, the term "thickness" in this context should be considered an average thickness. Finally, we assume that the density of the interior part of a particle surrounded by an oxygenated layer is similar to that for the total particle. This assumption is generally valid if the oxygenated layer is very thin. The total averaged absorbance at the resonance energies of carboxylic $\mathrm{C}$ and O-alkyl-C functional groups can then be considered as a sum of two absorbencies: averaged absorbance through the oxygenated shell of thickness $\Delta$ and density $\rho_{\text {sh }}$ and averaged absorbance through a spherical particle of diameter $(d-2 \Delta)$ and an averaged particle density $\rho$. By assuming that the shell thickness is much smaller than the particle diameter, we neglect the case when the X-ray beam propagates only through the shell and the averaged absorbance $<\mathrm{OD}_{\mathrm{sh}}(E)>$ at a photon energy $E$ through the shell can be calculated from the following equation:

$$
\begin{aligned}
\left\langle\mathrm{OD}_{\mathrm{sh}}(E)\right\rangle \approx \frac{2}{d} \int_{-d / 2}^{d / 2} \rho_{\mathrm{sh}} \mu(E) \frac{d \Delta}{2 \sqrt{(d / 2)^{2}-x^{2}}} \mathrm{~d} x= \\
4 A \rho_{\mathrm{sh}} \mu(E) \Delta
\end{aligned}
$$

where $A$ is the constant $A=1 / 2 \sin (1) \approx 0.59$ and $\mu(E)$ is the difference in mass absorption coefficients at the resonance energy for either carboxylic $\mathrm{C}$ or O-alkyl-C functional groups and at the $\mathrm{C}$ pre-edge energy $(280 \mathrm{eV})$. From eq 1 , the averaged absorbance $\left\langle\mathrm{OD}_{\text {int }}(E)\right\rangle$ at a photon energy $E$ through the spherical interior portion of the particle with diameter $(d-2 \Delta)$ can be described as

$$
\left\langle\mathrm{OD}_{\text {int }}(E)\right\rangle=A \rho \mu(E)(d-2 \Delta)
$$

By combining eq 1 for the total $\mathrm{C}$ absorbance dependence on the particle diameter for the overall particle with eqs $5 \mathrm{a}$ and $5 \mathrm{~b}$, the normalized (to total carbon) intensity of either carboxylic $\mathrm{C}$ or O-alkyl-C functional groups as a function of particle diameter can be written as following:

$$
\frac{\mathrm{OD}(E)}{\mathrm{OD}_{\text {total C }}}=\frac{\mu(E)}{\mu_{320-280 \mathrm{eV}}}+\frac{2 \mu(E) \Delta\left[2\left(\rho_{\mathrm{sh}} / \rho\right)-1\right]_{1}}{\mu_{320-280 \mathrm{eV}} d}
$$

where $E$ is the resonance energies for the carboxylic $\mathrm{C}$ and $\mathrm{O}$-alkyl-C functional groups. Equation 6 suggests that the plot of normalized intensity of carboxylic $\mathrm{C}$ and $\mathrm{O}$-alkyl-C functional groups versus inverse particle diameter is linear with an intercept determined by the first term in eq 6 and a slope defined by the second term.
From eq 6, the analytical expression for the normalized intensity of the functional groups can be compared directly with the experimental results. The data for both functional groups are fit using the analytical expression in eq 6 and are shown as solid gray lines in Figure 9c,d. The determined slopes and intercepts from the fit (if data shown in Figure 9 would be plotted versus inverse diameter; data are not shown) are 0.11 $\pm 0.01 \mu \mathrm{m}^{-1}$ and $1.4 \pm 0.1$ for carboxylic $\mathrm{C}$ functional group and $0.1 \pm 0.01 \mu \mathrm{m}^{-1}$ and $1.2 \pm 0.1$ for the $\mathrm{O}$-alkyl-C functional group. These values are from the $\mathrm{C}$-edge data. As we measure a column (the product of density and thickness), we cannot independently determine both thickness of the oxygenated layer and density from the fitted values. Assuming that the density of the layer is similar to that for the total particle, eq 6 simplifies so that $\rho_{\mathrm{sh}} / \rho \approx 1$ and the ratio of the slope to the intercept is twice the layer thickness. From this analysis, layer thicknesses of $40 \pm 5 \mathrm{~nm}$ (carboxylic $\mathrm{C}$ functional group data) and $42 \pm 5$ $\mathrm{nm}$ (O-alkyl-C functional group data) are obtained. Excellent agreement between these two suggests that the analytical model for the quantification of an oxygenated layer on the particle interface is adequate to describe the observed dependencies. In addition, this agreement confirms the assumption that both functional groups are homogeneously distributed within the oxygenated layer at the same density.

The layer thickness of $\sim 41 \mathrm{~nm}$ was obtained assuming similar densities for the layer and overall particle. However, it is plausible that the layer density might be lower or higher than the particle core, which would modify the determined thickness. Hand et al. ${ }^{17}$ observed an enhancement in the oxygen content at the tar ball interface and determined semiquantitatively the thickness of the layer to be $\sim 30 \mathrm{~nm}$. This agrees well with the value determined by STXM/NEXAFS. If we consider the semiquantitatively determined value of $30 \mathrm{~nm}$ to be exact, then the density of the oxygenated layer required would be $\rho_{\mathrm{sh}} \approx$ $0.88 \mathrm{~g} / \mathrm{cm}^{3}$ instead of the $0.75 \mathrm{~g} / \mathrm{cm}^{3}$ used here. A larger value of oxygenated shell density required to obtain the same thickness result is consistent with the literature observations of the tendency of the density to increase with increasing oxygen content. ${ }^{40}$

The presence of the oxygenated surface layer is indicative of atmospheric processing of tar balls. As mentioned previously, tar balls sampled during the Yosemite Aerosol Characterization Study were aged two or more days during transport to the sampling site. Maria et al. speculated that atmospheric processing of organic aerosols results in larger concentration of carbonyl carbon at the particle surface. ${ }^{23}$ This is consistent with our finding of an enhanced concentration of carboxylic $\mathrm{C}$ at the tar ball interface and suggests that the layer originates from atmospheric processing. In addition, we performed both STXM and NEXAFS studies of tar balls collected in plumes from southern African fires ${ }^{15,16}$ (data are not shown), where the particles were sampled from fresh (a few hours old) biomass smoke. The NEXAFS spectral contours of a "fresh" tar ball were similar to the acid standards (Figure 8). The O-alkyl-C peak, observed in the aged tar balls (Yosemite Study), was not seen in the acid standards. Cursory analysis similar to that performed above was applied to the fresh tar balls and no oxygenated interface layer was identified, dissimilar to the tar balls from the Yosemite Aerosol Characterization Study that were subject to prolonged atmospheric processing. This provides additional evidence that the oxygenated layer is primarily due to atmospheric processing of tar balls. The direct comparison between two types of tar balls is speculative, since the different 
formation temperatures and precursors could alter the initial chemical composition.

Owing to the polyacidic nature of HULIS, ${ }^{10}$ it is expected that the carboxylic carbonyl constituent of the tar balls ( $\sim 39 \%$ of all $\mathrm{C}$ functional groups) corresponds to or is at least a large fraction of polycarboxylic acids. This assumption is supported by recent studies that identified polycarboxylic acids in biomass burn aerosols. ${ }^{10,48} \mathrm{~A}$ high concentration of the polycarboxylic acids within the tar ball as well as on its interface has important implications for their potential role in cloud formation and subsequent climate forcing. Although some of the polycarboxylic acids could be insoluble, a significant fraction is watersoluble. A number of studies observed a significant decrease in surface tension with respect to pure water in wet aerosol and cloud/fog samples that was correlated with the presence of soluble polycarboxylic acids in the droplets. ${ }^{10,19}$ The surface tension reduction enhances $\mathrm{CCN}$ activity and could increase the surface volume of wet aerosols and, therefore, may have a profound effect on the indirect climate forcing. The high concentration of polycarboxylic acids in tar balls determined here, coupled with the surface tension effects and water solubility of polycarboxylic acids, suggests that tar balls should be water-soluble and may serve as $\mathrm{CCN}$ at atmospherically relevant supersaturation. The fact that the tar balls are watersoluble $^{17}$ and may serve as $\mathrm{CCN}$ supports the premise that polycarboxylic acids in biomass burn aerosols play an important role in their $\mathrm{CCN}$ activity without requiring the presence of other inorganic compounds.

\section{Conclusions}

We have presented an analytical method based on a combination of STXM and NEXAFS spectroscopy that allowed quantification of the shape, structure, and size-dependent chemical composition of individual biomass burn tar ball particles. Tar balls were unambiguously identified as high molecular weight humic-like substances and not soot. As these particles were collected during a time of high light absorption, this work supports the premise that humic-like substances and nongraphitic carbon species influence absorption measurements. Carboxylic carbonyl and O-alkyl-C are the dominant forms of organic carbon in tar balls, followed by moderate amounts of ketonic carbonyl and aromatic $\mathrm{C}$ functional groups. The high concentration of water-soluble polycarboxylic acids in tar balls explains their hygroscopic properties. The detailed examination of sizedependent chemical composition revealed a $\sim 40$-nm-thick oxygenated interface layer resulting from atmospheric processing of tar balls that enhances the concentration of carboxylic carbonyl and O-alkyl-C functional groups at the particle interface.

Acknowledgment. This work was supported by the U.S. Department of Energy's Atmospheric Science Program (Office of Science, BER) DOE. The work at the Advanced Light Source (ALS) of Lawrence Berkeley National Laboratory (LBNL) was supported by the Office of Science, Office of Basic Energy Sciences, the Division of Chemical Sciences, Geosciences, and Biosciences, and the Division of Materials Sciences of DOE at the ALS and LBNL under Contract No. DE-AC03-76S00098. We thank A. D. Kilcoyne for support at beamline 5.3.2. A. Laskin and J. L. Hand are gratefully acknowledged for supplying samples from the Yosemite Aerosol Characterization Study of summer 2002 as well as scientific discussions.

Supporting Information Available: Representative carbon and oxygen K-edge normalized NEXAFS spectra of tar ball (black line) and organic particle (gray line) (Figure S1). Typical particle profile as a function of the radial distance from the particle center (Figure S2). Particle size distribution for $\sim 150$ spherically shaped particles analyzed here (Figure S3). This material is available free of charge via the Internet at http:// pubs.acs.org.

\section{References and Notes}

(1) Bond, T. C.; Streets, D. G.; Yarber, K. F.; Nelson, S. M.; Woo, J.-H.; Klimont, Z. J. Geophys. Res., [Atmos.] 2004, 109, 14203.

(2) Andreae, M. O.; Gelencsér, A. Atmos. Chem. Phys. Discuss. 2006, 6,3419 .

(3) Bond, T. C.; Bergstrom, R. W. Aerosol Sci. Technol. 2006, 40, 27.

(4) Hoffer, A.; Gelencsér, A.; Guyon, P.; Kiss, G.; Schmid, O.; Frank, G.; Artaxo, P.; Andreae, M. O. Atmos. Chem. Phys. Discuss. 2005, 5, 7341.

(5) Mukai, H.; Ambe, Y. Atmos. Environ. 1986, 20, 813.

(6) Havers, N.; Burba, P.; Lambert, J.; Klockow, D. Chromatographia 1998, 47, 619 .

(7) Zappoli, S.; Andracchio, A.; Fuzzi, S.; Facchini, M. C.; Gelencsér, A.; Kiss, G.; Krivácsy, Z.; Molnár, A.; Mészáros, E.; Hansson, H. C.; Rosman, K.; Zebühr, Y. Atmos. Environ. 1999, 33, 2733.

(8) Kiss, G.; Varga, B.; Gelencsér, A.; Krivàcsy, Z.; Molnàr, A.; Alsberg, T.; Persson, L.; Hansson, H. C.; Facchini, M. C. Atmos. Environ. 2001, 35, 2193

(9) Graber, E. R.; Rudich, Y. Atmos. Chem. Phys. 2006, 6, 729.

(10) Mayol-Bracero, O. L.; Guyon, P.; Graham, B.; Roberts, G.; Andreae, M. O.; Decesari, S.; Facchini, M. C.; Fuzzi, S.; Artaxo, P. J. Geophys. Res., [Atmos.] 2002, 107, 8091.

(11) Gelencser, A.; Hoffer, A.; Kiss, G.; Tombacz, E.; Kurdi, R.; Bencze, L. J. Atmos. Chem. 2003, 45, 25.

(12) Andreae, M. O.; Artaxo, P.; Fischer, H.; Freitas, S. R.; Gregoire J. M.; Hansel, A.; Hoor, P.; Kormann, R.; Krejci, R.; Lange, L.; Lelieveld, J.; Lindinger, W.; Longo, K.; Peters, W.; de Reus, M.; Scheeren, B.; Dias, M.; Strom, J.; van Velthoven, P. F. J.; Williams, J. Geophys. Res. Lett. 2001, 28, 951 .

(13) Andreae, M. O.; Rosenfeld, D.; Artaxo, P.; Costa, A. A.; Frank, G. P.; Longo, K. M.; Silva-Dias, M. A. F. Science 2004, 303, 1337.

(14) Jones, G. S.; Jones, A.; Roberts, D. L.; Stott, P. A.; Williams, K. D. Geophys. Res. Lett. 2005, 32, L14701.

(15) Pósfai, M.; Simonics, R.; Li, J.; Hobbs, P. V.; Buseck, P. R. J Geophys. Res., [Atmos.] 2003, 108, 8483.

(16) Pósfai, M.; Gelencsér, A.; Simonics, R.; Arató, K.; Li, J.; Hobbs, P. V.; Buseck, P. R. J. Geophys. Res., [Atmos.] 2004, 109, 6213.

(17) Hand, J. L.; Malm, W. C.; Laskin, A.; Day, D.; Lee, T.; Wang, C.; Carrico, C.; Carrillo, J.; Cowin, J. P.; Collett, J.; Iedema, M. J. J. Geophys. Res., [Atmos.] 2005, 110, 21210.

(18) Stöhr, J. NEXAFS Spectroscopy, 1st ed.; Springer-Verlag: Berlin Heidelberg, 2003.

(19) Ma, Y.; Chen, C. T.; Meigs, G.; Randall, K.; Sette, F. Phys. Rev. A 1991, 44, 1848

(20) Hopkins, R. J.; Tivanski, A. V.; Gilles, M. K. J. Aerosol Sci., in press.

(21) Michelson, H. A.; Tivanski, A. V.; Gilles, M. K.; van Poppel, L. H.; Dansson, M. A.; Buseck, P. R. Appl. Opt. 2007, 46, 959.

(22) Solomon, D.; Lehmann, J.; Kinyangi, J.; Liang, B. Q.; Schafer, T Soil Sci. Soc. Am. J. 2005, 69, 107.

(23) Maria, S. F.; Russell, L. M.; Gilles, M. K.; Myneni, S. C. B. Science 2004, 306, 1921.

(24) Boyce, C. K.; Cody, G. D.; Feser, M.; Jacobsen, C.; Knoll, A. H.; Wirick, S. Geology 2002, 30, 1039.

(25) Jokic, A.; Cutler, J. N.; Ponomarenko, E.; van der Kamp, G.; Anderson, D. W. Geochim. Cosmochim. Acta 2003, 67, 2585.

(26) Myneni, S. C. B. Rev. Mineral. Geochem. 2002, 49, 485.

(27) Braun, A.; Shah, N.; Huggins, F. E.; Huffman, G. P.; Wirick, S.; Jacobsen, C.; Kelly, K.; Sarofim, A. Fuel 2004, 83, 997.

(28) di Stasio, S.; Braun, A. Energy Fuels 2006, 20, 187.

(29) Russell, L. M.; Maria, S. F.; Myneni, S. C. B. Geophys. Res. Lett. 2002, 29, 1779 .

(30) Cody, G. D.; Ade, H.; Wirick, S.; Mitchell, G. D.; Davis, A. Org Geochem. 1998, 28, 441.

(31) Urquhart, S. G.; Ade, H. J. Phys. Chem. B 2002, 106, 8531.

(32) Lessard, R.; Cuny, J.; Cooper, G.; Hitchcock, A. P. Chem. Phys. 2007, 331, 289.

(33) Henke, B. L.; Lee, P.; Tanaka, T. J.; Shimabukuro, R. L.; Fuikawa, B. K. At. Data Nucl. Data Tables 1982, $27,1$.

(34) Sodhi, R. N. S.; Brion, C. E. J. Electron Spectrosc. Relat. Phenom. 1985, 37,1 .

(35) Sodhi, R. N. S.; Brion, C. E. J. Electron Spectrosc. Relat. Phenom. 1985, 36, 187. 
(36) Radke, L. F.; Hegg, D. A.; Hobbs, P. V.; Nance, J. D.; Lyons, J. H.; Laursen, K. K.; Weiss, R. E.; Riggan, P. J.; Ward, D. E. Particulates and Trace Gas Emissions from Large Biomass Fires in North America, in Global Biomass Burning: Atmospheric, Climatic, and Biospheric Implications; Levine, J. S., Ed.; MIT Press: Cambridge, MA, 1991.

(37) Guyon, P.; Graham, B.; Beck, J.; Boucher, O.; Gerasopoulos, E.; Mayol-Bracero, O. L.; Roberts, G. C.; Artaxo, P.; Andreae, M. O. Atmos. Chem. Phys. 2003, 3, 951.

(38) Malm, W. C.; Day, D. E.; Carrico, C.; Kreidenweis, S. M.; Collett, J. L., Jr.; McMeeking, G.; Lee, T.; Carrillo, J.; Schichtel, B. J. Geophys. Res., [Atmos.] 2005, 110, 14302.

(39) Rice, J. A.; MacCarthy, P. Org. Geochem. 1991, 17, 635.

(40) Dinar, E.; Mentel, T. F.; Rudich, Y. Atmos. Chem. Phys. Discuss. 2003, 3, 951 .

(41) Rosenberg, R. A.; Love, P. J.; Rehn, V. Phys. Rev. B 1986, 33, 4034.
(42) Lenardi, C.; Marino, M.; Barborini, E.; Piseri, P.; Milani, P. Eur. Phys. J. B 2005, 46, 441 .

(43) Ahuja, R.; Bruhwiler, P. A.; Wills, J. M.; Johansson, B.; Martensson, N.; Eriksson, O. Phys. Rev. B 1996, 54, 14396.

(44) Willis, R. F.; Fitton, B.; Painter, G. S. Phys. Rev. B 1974, 9, 1926.

(45) Coffman, F. L.; Cao, R.; Pianetta, P. A.; Kapoor, S.; Kelly, M.; Terminello, J. L. Appl. Phys. Lett. 1996, 69, 568.

(46) Facchini, M. C.; Fuzzi, S.; Zappoli, S.; Andracchio, A.; Gelencsér, A.; Kiss, G.; Krivácsy, Z.; Mészáros, E.; Hansson, H.-C.; Alsberg, T.; Zebühr, Y. J. Geophys. Res., [Atmos.] 1999, 104, 26821.

(47) Chang, H.; Charalampopoulos, T. T. Proc. R. Soc. London, Ser. A 1990, 430, 577 .

(48) Fang, M.; Zheng, M.; Wang, F.; To, K. L.; Jaafar, A. B.; Tong, S. L. Atmos. Environ. 1999, 33, 783. 


\section{Supporting Information}

\section{Oxygenated Interface on Biomass Burn Tar Balls Determined by Single Particle Scanning Transmission X-ray Microscopy}

Alexei V. Tivanski, Rebecca J. Hopkins, Tolek Tyliszczak and Mary K. Gilles
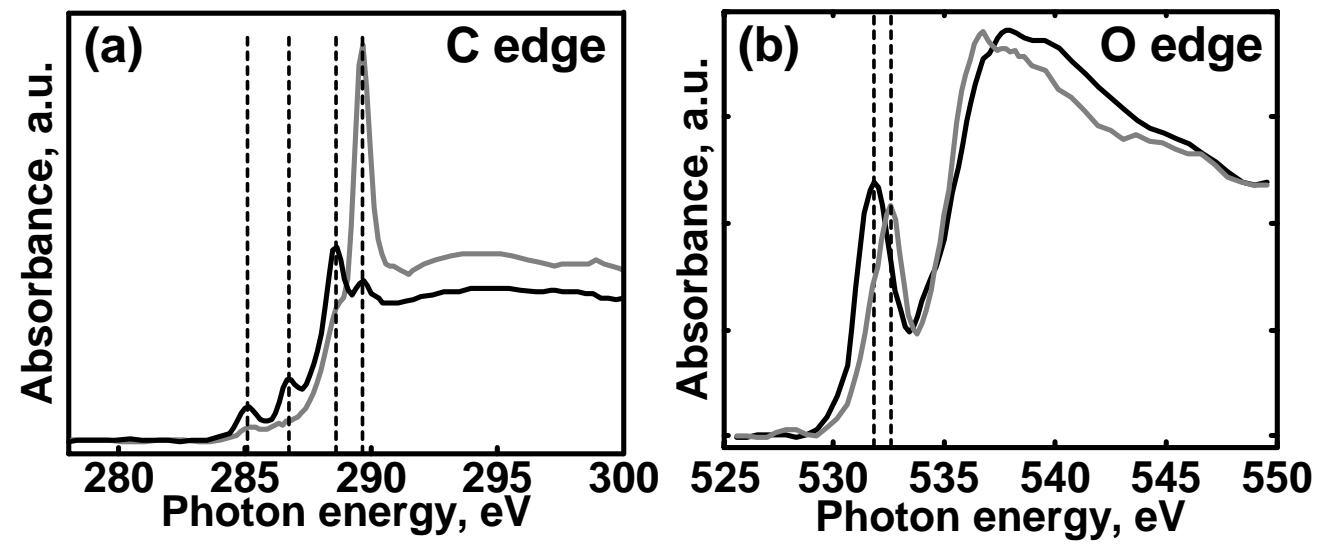

Figure S1. Representative carbon (a) and oxygen (b) K-edge normalized NEXAFS spectra of tar ball (black line) and organic particle (grey line). Vertical dotted lines indicate the absorbance energies, from left to right, at 285.1, 286.7, 288.5 and $289.5 \mathrm{eV}$ for the carbon edge, and 531.8 and $532.5 \mathrm{eV}$ for the oxygen edge.

\section{Determination of individual particle size and corresponding size distribution}

Due to the finite resolution of STXM (typically $35 \mathrm{~nm}$ ), the convolution of the x-ray beam size and particle edge limits exact determination of the particle size. This limitation is especially important for particles smaller than 200 nm, where the uncertainty in the particle diameter can be as large as several tens of percent. Here, we use an alternative method to analytically determine the particle diameter from the radial profile from STXM images recorded at the carbon post-edge energy of $320 \mathrm{eV}$. By manually determining the particle center then averaging the cross-section profile through the center,

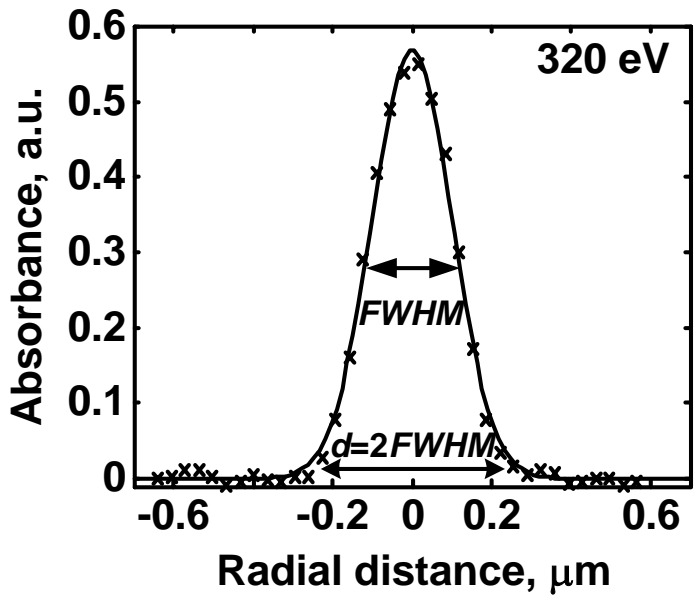

Figure S2. Particle profile as a function of the radial distance from the particle center. Crosses are the data and the solid line is the Gaussian curve fit. Particle diameter is defined as twice the FWHM. 
at angles from $0^{\circ}$ to $360^{\circ}$ at $3^{\circ}$ increments, a radial profile is obtained. The resulting particle profile is fit with a Gaussian function. A typical profile, with a full width half maximum (FWHM) of $\sim 240 \mathrm{~nm}$, is shown in Figure S2. Data is represented by symbols and the Gaussian fit by the solid line. As the FWHM can be determined accurately with an uncertainty that does not vary significantly with particle size, we define the particle diameter as twice the FWHM, as illustrated in Figure S2.

Particle diameters determined for $\sim 150$ spherical particles yield the particle size distribution shown in Figure S3. The size distribution was obtained by sorting particles into $\sim 80 \mathrm{~nm}$ wide bins according to particle diameter. The fit of the distribution to a Gaussian function is shown by the solid line in Figure S3. From the fit, the bin with the largest number of particles is $D_{\max }=0.5 \pm 0.15 \mu \mathrm{m}$.

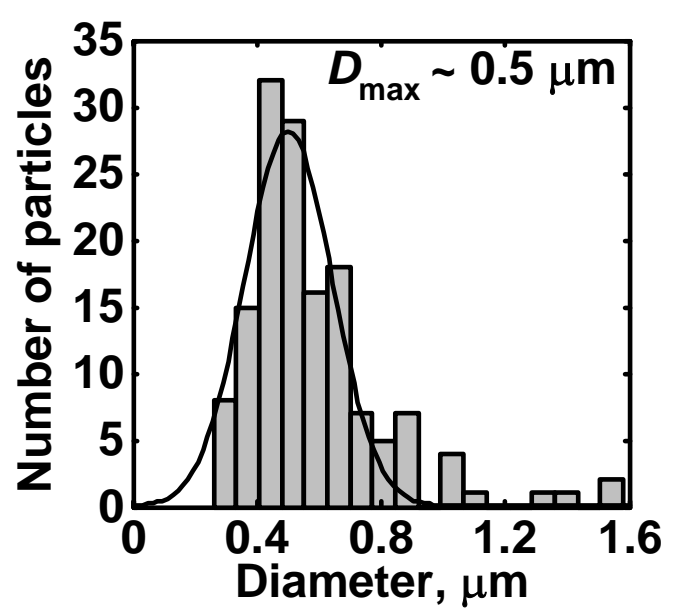

Figure S3. Particle size distribution for 150 spherically shaped particles analyzed. Solid line is the Gaussian fit. 